\title{
Re-analysis of the "Akron" Airship Pressure Data to Design Pressure Measurement Experiments on an Underwater Vehicle
}

\author{
F. Azarsina ${ }^{1}$, C.D. Williams ${ }^{2}$, D. Bass ${ }^{3}$, N. Bose $^{4}$ \\ ${ }^{1} \mathrm{PhD}$ Candidate, Faculty of Engineering and Applied Science, Memorial University of Newfoundland \\ e-mail: Farhood.Azarsina@nrc.ca \\ ${ }^{2}$ Research Engineer, National Research Council Canada, Institute for Ocean Technology \\ e-mail: Christopher.Williams@nrc-cnrc.gc.ca \\ ${ }^{3}$ Professor, Faculty of Engineering and Applied Science, Memorial University of Newfoundland \\ e-mail: Dbass@engr.mun.ca \\ ${ }^{4}$ Professor of Maritime Hydrodynamics, Australian Maritime Hydrodynamics \\ Research Centre, Australian Maritime College \\ e-mail: N.Bose@amc.edu.au
}

\begin{abstract}
Pressure experimental data from NACA tests on the airship "Akron" were reanalysed in this study. The pressure distribution over the bare hull of the airship were presented by using 3D pressure surfaces and 2D pressure contours for different pitch angles. By integration of the normal pressures at each panel over the bare hull of the airship, the axial and normal forces and the pitching moment exerted on the hull were derived. The paper has a brief introduction on how to use this re-analysis of the old experiment data to plan pressure-measurement experiments on an underwater vehicle.
\end{abstract}

\section{NOMENCLATURE}

d Airship maximum diameter [m]

1 Airship overall length [m]

$\mathrm{x}$ Distance from airship nose [m]

$\mathrm{r}(\mathrm{x})$ Airship radius [m]

$\mathrm{p}_{\text {total }}$ Total pressure measured at each orifice $[\mathrm{Pa}]$

$\mathrm{p}_{\mathrm{S}}$ Static pressure along the centreline of the wind-tunnel test section $[\mathrm{Pa}]$

$\mathrm{p}$ Dynamic pressure measured at each orifice $[\mathrm{Pa}]$

$\mathrm{q}_{0}$ Dynamic pressure of the free air stream $[\mathrm{Pa}]$

$\mathrm{V}$ Free air stream velocity $[\mathrm{m} / \mathrm{s}]$

$\mathrm{F}_{\mathrm{x}}$ Axial force $[\mathrm{N}]$

$\mathrm{F}_{\mathrm{z}}$ Normal force $[\mathrm{N}]$

D Drag force $[\mathrm{N}]$

L Lift force $[\mathrm{N}]$

$\mathrm{M}_{\mathrm{y}}$ Pitching moment about an axis through the center of buoyancy (CoB) [N.m]

$\rho$ Dry air mass density (assumed at $25 \mathrm{C}^{\circ}$ and $100 \mathrm{kPa}$ equal to $1.168 \mathrm{~kg} / \mathrm{m}^{3}$ )

$\omega$ Circumferential angle around the airship cross-sections [deg]; positive counterclockwise when looking aftward

$\theta \quad$ Airship pitch angle [deg]; positive nose up

$\varphi \quad$ Airship surface slope along longitudinal generators $[\mathrm{deg}] ; \tan (\varphi)=\mathrm{dr} / \mathrm{dx}$

\section{INTRODUCTION}

From 1929 to 1932, a series of very extensive and valuable experiments were performed in the wind tunnel of the U.S. National Advisory Committee for Aeronautics (NACA) on some airship models, including a 1/40-scale model of the U.S. Airship "Akron". One set of experiments, [1], on the Akron airship was designed to determine the drag force, lift force and pitching moment on the bare hull and hull with appendages. In another set of experiments, [2], a 1/40-scale model of the ZRS-4 airship was used to study pressure distributions. The Akron airship model had a length of $5.98 \mathrm{~m}$ (19.62 ft) and had a maximum diameter 
of $1 \mathrm{~m}(3.32 \mathrm{ft})$; therefore the model had a length-to-diameter ratio (1/d) of 5.9. Pressure data were recorded for a nominal air speed of $100 \mathrm{mph}$ equivalent to $44.7 \mathrm{~m} / \mathrm{s}$ in the 20 -foot (6 metres) propeller-research wind tunnel of the National Advisory Committee for Aeronautics and were completed in July 1931 [2].

This research used up-to-date numerical methods and tools to re-analyze the data from the "Akron" pressure experiment. The data extracted from NACA report No. 443 included the geometrical shape of the bare hull and the variation of the pressures measured on the surface of the bare hull at about 400 locations and at eight pitch angles. The geometric data includes the shape of the bare hull, that is, the variation of the hull radius over its length. The pressure data included the ratio $p / q_{0}$, where $p$ is the dynamic pressure measured at each orifice, and $\mathrm{q}_{0}$ is the dynamic pressure of the free stream:

$$
\mathrm{q}_{0}=(1 / 2) \rho \mathrm{V}^{2} \text {. }
$$

where $\rho$ is the air mass density and $\mathrm{V}$ is the free stream velocity.

In this study, in order to integrate the measured normal pressures over the surface of the bare hull of the airship, it was meshed by panels. Normal pressure integration results in the pressure drag only, however about 80 percent of the drag force is due to the viscous effects. Viscous properties of the flow from another set of experiments on the $1 / 40$-scale model of the airship Akron were observed and reported [3].

\section{FitTING CURVES To THE EXPERIMENTAL DATA}

\section{A. Airship geometry and arrangement of the orifices}

About 400 pressure orifices, distributed longitudinally over 26 transverse stations, on the port half of each station, simultaneously recorded the local pressure on the airship hull both with and without control surfaces fitted to the model. Eight angles of pitch ' $\theta$ ' of the bare hull of $0,3,6,9,12,15,18$ and 20 degrees and two air speeds of about 70 and $100 \mathrm{mph}(31.3$ and $44.7 \mathrm{~m} / \mathrm{s}$ ) were used. In these experiments the model angle of attack was restricted to variations of the pitch angle only; the effects of changes in yaw or roll attitude were not investigated.

Table I and Fig. 1 show the location of stations along the airship model, and Fig. 2 shows the location of the orifices around each station. The different front views shown in Fig. 2 are due to the different arrangement of the orifices at different stations. Some stations in each group include the orifices marked " $\mathrm{X}$ " so as to check for the equality of pressures on the port and starboard sides. The orifices were $0.8 \mathrm{~mm}(1 / 32 \mathrm{inch})$ in diameter.

TABLE I

Measurment Stations And Their Axial Location

\begin{tabular}{|c|c|c|c|c|c|c|c|c|c|c|c|c|c|c|}
\hline Station No. & 1 & 2 & 3 & 4 & 5 & 6 & 7 & 8 & 9 & 10 & 11 & 12 & 13 & 14 \\
\hline Axial location $[\mathrm{m}]$ & 0 & 0.035 & 0.087 & 0.143 & 0.221 & 0.306 & 0.454 & 0.662 & 0.913 & 1.189 & 1.480 & 1.838 & 2.244 & 2.704 \\
\hline $\mathrm{x} / 1$ & 0 & 0.006 & 0.015 & 0.024 & 0.037 & 0.051 & 0.076 & 0.111 & 0.153 & 0.199 & 0.248 & 0.307 & 0.375 & 0.452 \\
\hline
\end{tabular}

Contd.

\begin{tabular}{|c|c|c|c|c|c|c|c|c|c|c|c|}
\hline 15 & 16 & 17 & 18 & 19 & 20 & 21 & 22 & 23 & 24 & 25 & 26 \\
\hline 3.211 & 3.719 & 4.232 & 4.536 & 4.775 & 5.035 & 5.187 & 5.372 & 5.533 & 5.676 & 5.819 & 5.918 \\
\hline 0.537 & 0.622 & 0.708 & 0.759 & 0.798 & 0.842 & 0.867 & 0.898 & 0.925 & 0.949 & 0.973 & 0.990 \\
\hline
\end{tabular}

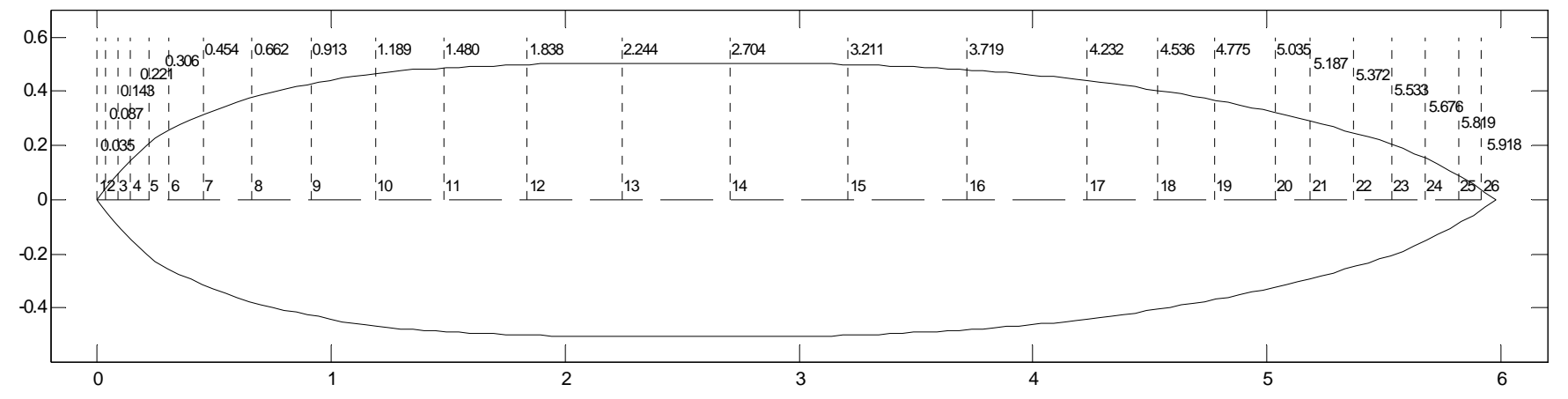

Fig. 1. Location of measurement stations in metres [2] 

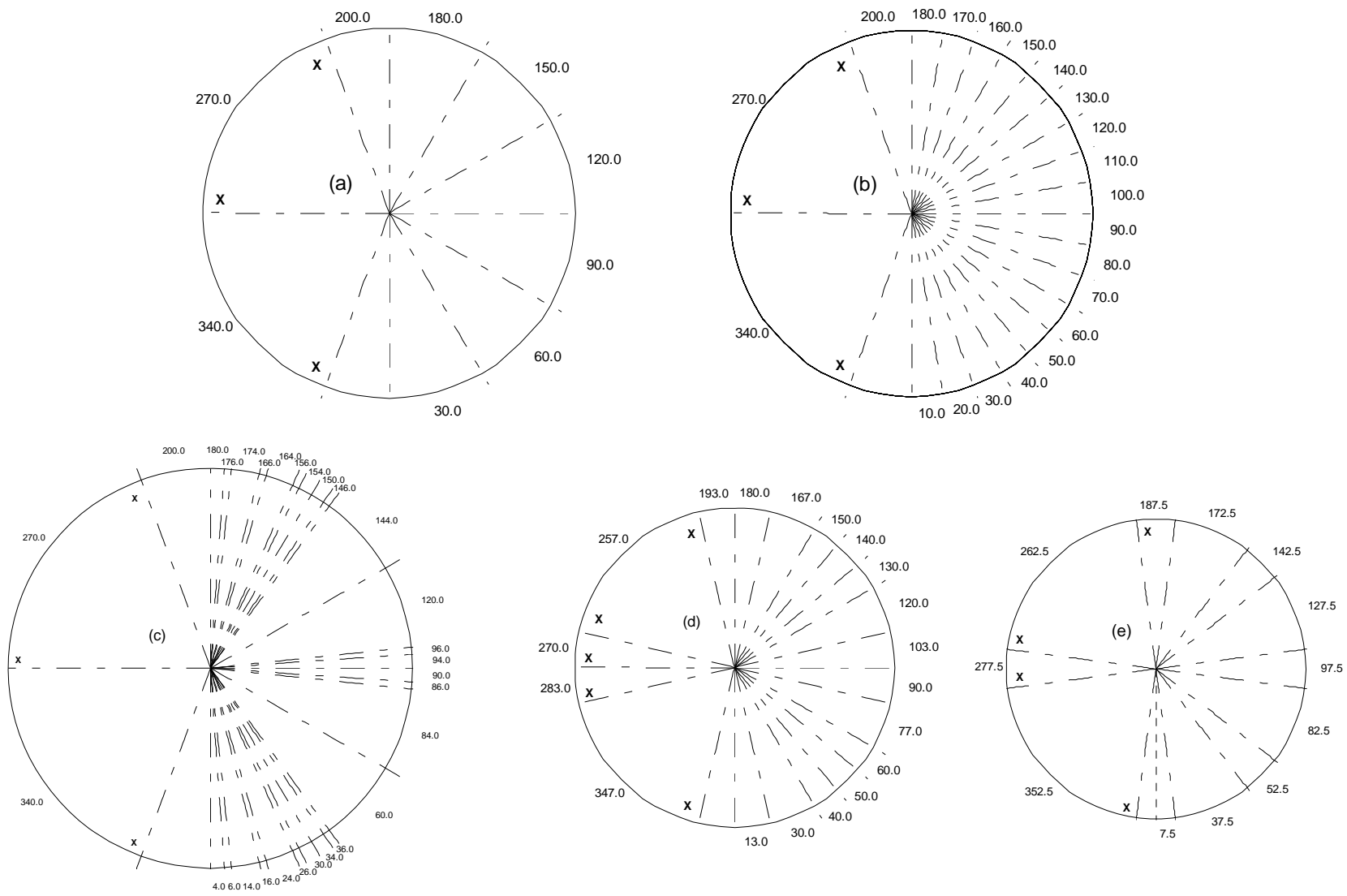

Fig. 2. Angular position of the orifices at different transverse stations; all views looking aftward (locations marked "X" are orifices to check the flow symmetry): (a) Stations 2, 3, 4, 6, 10, 14 and 16; (b) stations 5, 7, 9, 11, 13, 15 and 17; (c) stations 8 and 12;

(d) Stations 18 to 21 inclusive; (e) stations 22 to 26 inclusive [2]

\section{B. Fitting curves to the data around each station}

As mentioned, $\mathrm{p} / \mathrm{q}_{0}$, the ratio of dynamic pressure measured at each orifice to the dynamic pressure of the free stream was the main measured data in the Akron tests. Fig. 3 (a) to (c) show the variation of the recorded data, $\mathrm{p} / \mathrm{q}_{0}$, versus angular position of the orifices, namely the azimuth angle, $\omega$, for stations number 8,14 (mid-body), and 25 (in the stern). The azimuth angle varies from zero at the airship keel, to 180 degrees at the airship top-line. Measured data are marked according to the legend for different pitch angles. The curves fitted are all of the form:

$$
\text { Fit }=A+B^{*} \cos (\omega)+C^{*}[\cos (\omega)]^{2}+D^{*}[\cos (\omega)]^{3}
$$

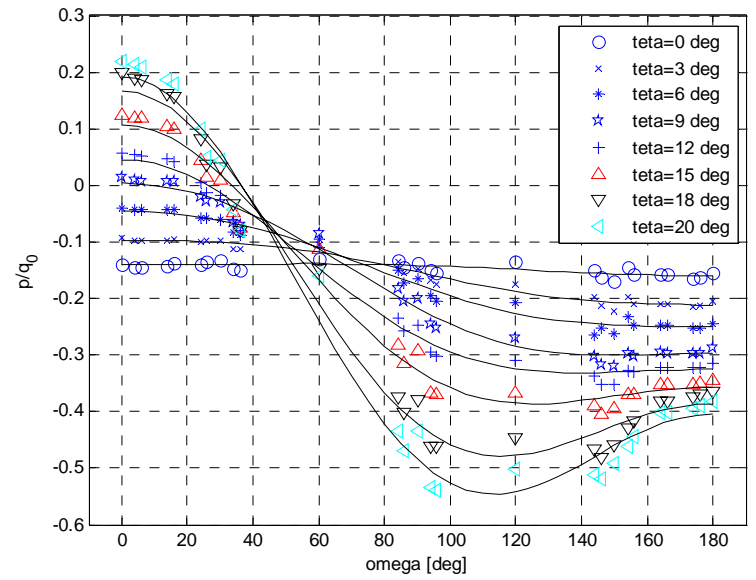

Fig. 3(a). Variation of the recorded data, $\mathbf{p} / \mathbf{q}_{0}$, versus angular position of the orifices, at Station 8

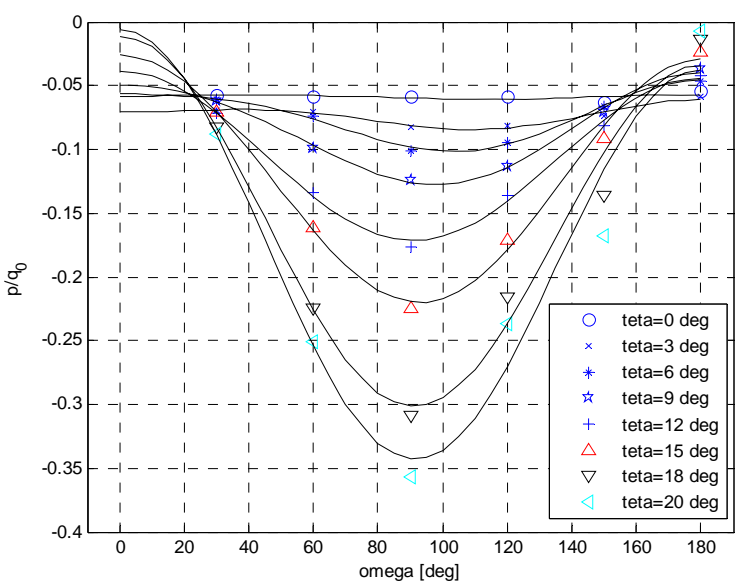

Fig. 3(b). Variation of the recorded data, $\mathbf{p} / \mathbf{q}_{0}$, versus angular position of the orifices, at Station 14 
The fitted curves in Fig. 3(a) match the data very closely. The data in Fig. 3(b) show that at large pitch angles there are some discrepancies between the fitted curves and the experimental data. In Fig. 3(c) further back towards the stern where the level of flow turbulence is high, the fitted curves intersect each other and get somewhat disordered for larger pitch angles. However, this fitting equation has good correlation with the experimental data for all stations. Fig. 4 shows the average correlation coefficient for the fitted curves over eight pitch angles for stations 2 to 26.

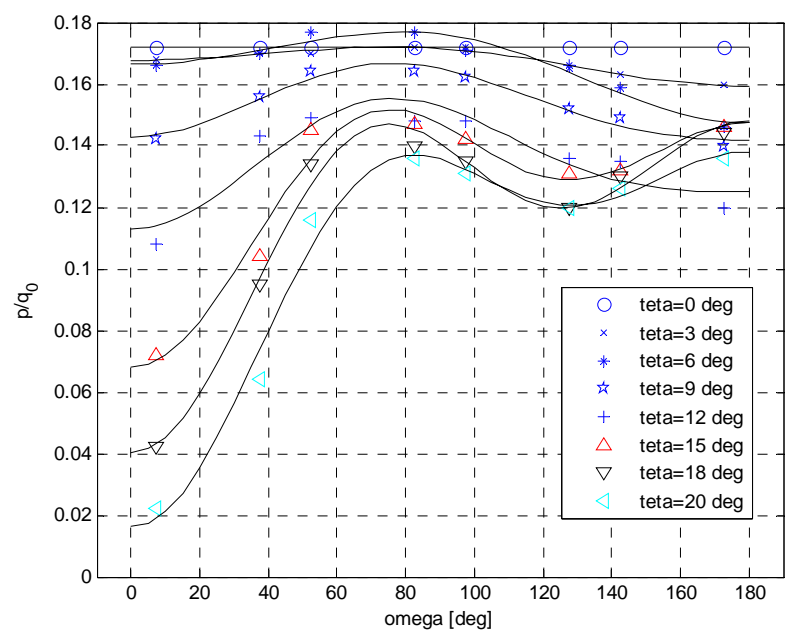

Fig. 3(c). Variation of the recorded data, $p / q_{0}$, versus angular position of the orifices, at Station 25

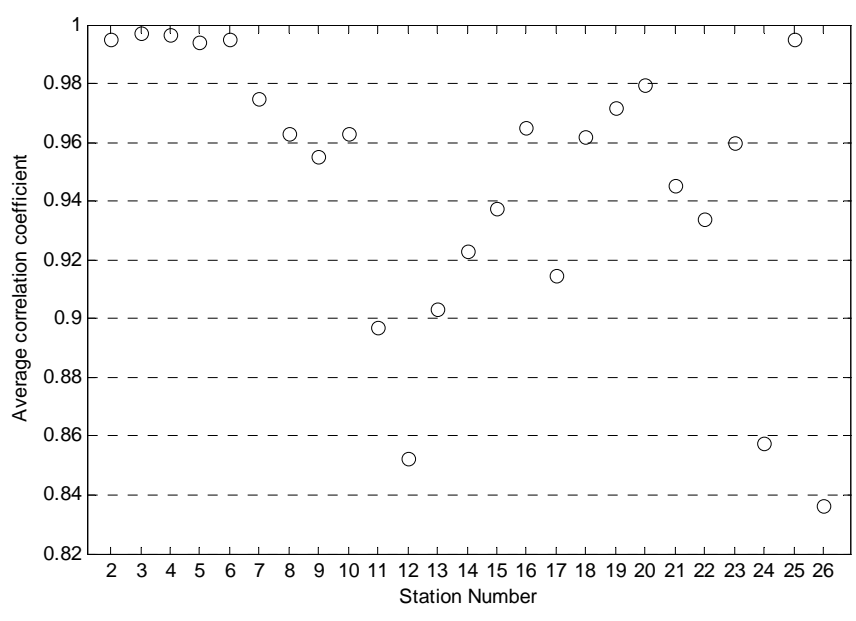

Fig. 4. Average correlation coefficient for the fitted curves by equation (2) over eight pitch angles for each station

Next the fitted curves were used to develop curves of the variation of pressure along generator lines along the surface of the hull. A generator line should be a smooth curve along the hull showing the variation of $\mathrm{p} / \mathrm{q}_{0}$. Having the coefficients of the fitted curves from equation (2) for stations 2 to 26 for eight pitch angles, fitted values of $\mathrm{p} / \mathrm{q}_{0}$ could be calculated for any desired value of the circumferential angle. At this point, it had to be decided what angular increment, $\Delta \omega$, was desired. Fitted values of $\mathrm{p} / \mathrm{q}_{0}$ for a pitch angle of 15 degrees and an azimuth angle of 180 degrees are shown in Fig. 5. Fitted values are marked by asterisks and experimental data by circles.

Experimental data were not available for every azimuth angle, e.g. for $\Delta \omega=5 \mathrm{deg}$ and $\omega=45 \mathrm{deg}$ no measurements were taken but still equation (2) fits values to $\mathrm{p} / \mathrm{q}_{0}$. Only for station number 1 , that is at the airship nose, is the fitted value the same as the experimental data. Table II shows the experimental measurements at the airship nose, station number 1, for all pitch angles. The method of reporting the experimental data included subtraction of the static pressure which was measured at each station along the centerline of the wind-tunnel without the model in the test section; see Fig. 6 and Table III. Thus the tabulated values for $\mathrm{p} / \mathrm{q}_{0}$ were corrected for the effects of the longitudinal gradient of static pressure. The result is that the ratio $\mathrm{p} / \mathrm{q}_{0}$ at the airship nose is unity at a pitch angle of zero as shown in Table II.

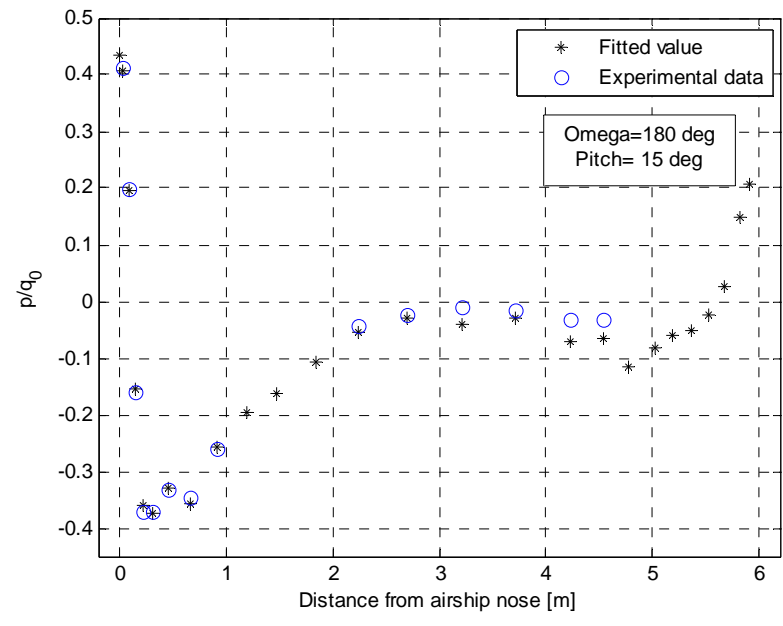

Fig. 5. Fitted values of $p / q_{0}$ along the hull compared to the experimental data; $\theta=15^{\circ}$ and $\omega=180^{\circ}$

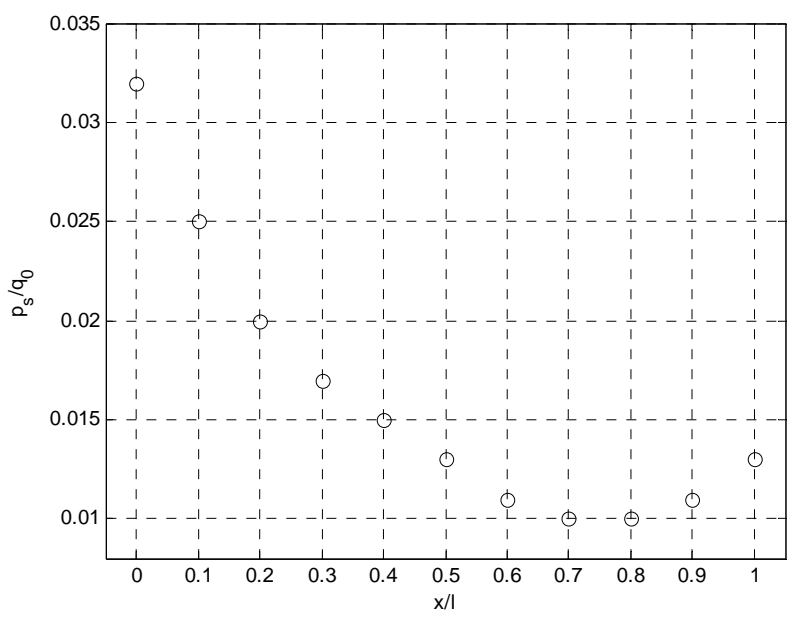

Fig. 6. Variation of the static pressure in the test section without the model present 
TABLE II

Dynamic Pressure Measured at the Airship Nose for Eight Pitch Angles

\begin{tabular}{|c|c|c|c|c|c|c|c|c|}
\hline Pitch angle $[\mathrm{deg}]$ & 0 & 3 & 6 & 9 & 12 & 15 & 18 & 20 \\
\hline $\mathrm{p} / \mathrm{q}_{0}$ & 1.000 & 0.967 & 0.900 & 0.785 & 0.682 & 0.434 & 0.098 & -0.132 \\
\hline
\end{tabular}

TABLE III

Static Pressure Distribution Along the Longitudinal Centreline of the Test Section in the Absence of the Airship

\begin{tabular}{|c|c|c|c|c|c|c|c|c|c|c|c|}
\hline $\mathrm{x} / 1$ & 0 & 0.1 & 0.2 & 0.3 & 0.4 & 0.5 & 0.6 & 0.7 & 0.8 & 0.9 & 1.0 \\
\hline $\mathrm{p}_{\mathrm{S}} / \mathrm{q}_{0}$ & 0.032 & 0.025 & 0.020 & 0.017 & 0.015 & 0.013 & 0.011 & 0.010 & 0.010 & 0.011 & 0.013 \\
\hline
\end{tabular}

\section{Fitting $9^{\text {th }}$ order polynomials to the pressure data along the airship hull}

Now smooth generator curves can be fitted to the discrete fitted values that were obtained at each station by fitting equation (2) to the experiments data; these points are shown by asterisks in the previous figures. Polynomials of $9^{\text {th }}$ order were used to fit the values of $\mathrm{p} / \mathrm{q}_{0}$, which were themselves fitted values to the experimental data. The $9^{\text {th }}$ order polynomial fit is the final pressure generator equation to be used in the panel method. The polynomial curve itself is a discrete series of values fitted over the longitudinal coordinate $\mathrm{x}$ by an increment of $\Delta \mathrm{x}$. For example, the polynomial representation is shown in Fig. 7 for a pitch angle of zero and azimuth angle of 90 degrees, and in Fig. 8 for a pitch angle of 15 degrees and azimuth angle 180 degrees. Note that due to the high order of the polynomial, care must be taken not to use this to predict pressures outside of the range of the input data.

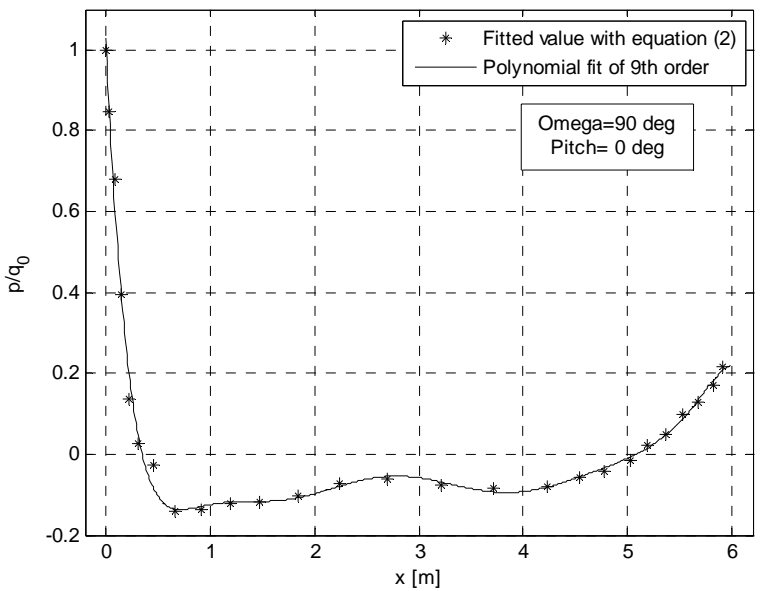

Fig. 7. Polynomials of $9^{\text {th }}$ order (solid line) fitted to the $p / q_{0}$ values (asterisks) fitted by equation (2); $\theta=0^{\circ}$ and $\omega=90^{\circ}$

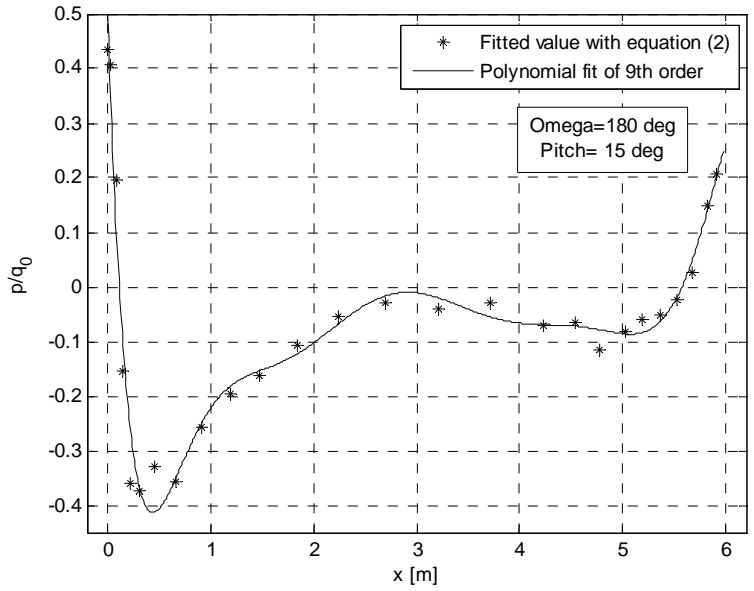

Fig. 8. Polynomials of $9^{\text {th }}$ order (solid line) fitted to the $p / q_{0}$ values (asterisks) fitted by equation (2); $\theta=15^{\circ}$ and $\omega=180^{\circ}$

\section{Geometry of the panels}

The angular increment from which the generator curves were produced, determines the size of one side of the surface panels, and the increment $\Delta \mathrm{x}$ by which the polynomial curve was defined, determines the size of the other side of the panels. Thus one side is of dimension $r \cdot \Delta \omega$, where $r$ is the radius of the hull cross-section, and, the second side is of dimension $\Delta x / \cos (\varphi)$, where $\varphi$ is the angle between the tangent line to the surface of the hull and the longitudinal axis. The meshed surface obtained using the surface-panel method is shown in Fig. 9. A tangent to the meshed surface at the bow end should have a 90 degree slope, whereas a curve fitted to the as-constructed shape has a slope of about 0.9 radian $\left(52^{\circ}\right)$ at the bow end.

Fig. 9 shows the 3D view of the meshed airship for longitudinal increment of $0.1 \mathrm{~m}$ and angular increment of $10^{\circ}$. In this study the $\mathrm{x}$-axis is positive toward the stern, the $\mathrm{y}$-axis is positive to starboard and the $\mathrm{z}$-axis is positive upward; these axes do not follow the SNAME convention for underwater vehicles [4].

In summary, the area of each panel is derived as

$$
\Delta \mathrm{A}=(\Delta \mathrm{x} / \cos (\varphi)) \cdot(\mathrm{r} \cdot \Delta \omega)
$$

where $\varphi=\varphi(x)$ and $r=r(x)$ hence:

$$
\Delta \mathrm{A}=\Delta \mathrm{A}(\mathrm{x})
$$

According to equation (4) the panel size depends only on the longitudinal distance from the airship nose. In equation (3), the longitudinal side of each panel, $\Delta \mathrm{x} / \cos (\varphi)$, is approximated as a straight line; hence, the error in calculating $\Delta \mathrm{A}$ increases as the incremental value of $\Delta \mathrm{x}$ increases, but the incremental value of $\Delta \omega$ does not affect the surface area value, because $\mathrm{r} \cdot \Delta \omega$ is the exact arc length of the lateral side of each panel. 


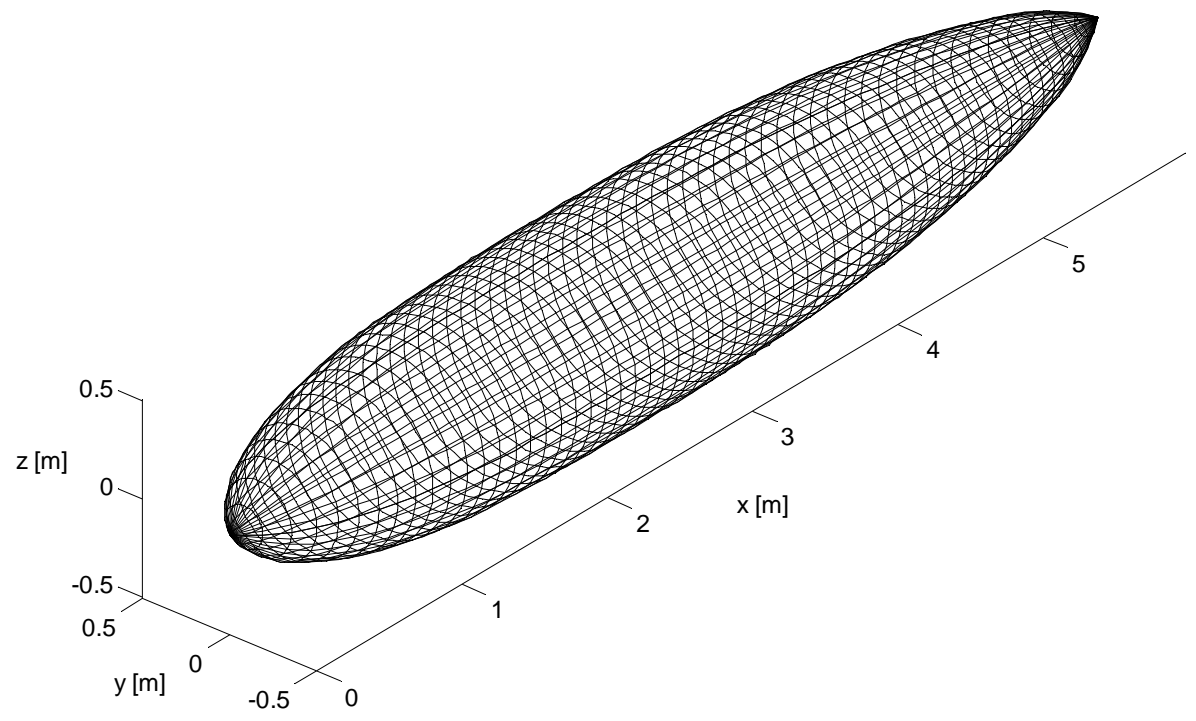

Fig. 9. Isometric view of the Akron airship hull meshed according to $\Delta \omega=10$ deg and $\Delta x=0.1 \mathrm{~m}$

\section{PRESSURE SURFACE ILLUSTRATION}

The pressure data can be illustrated by surfaces as in Figs. 10 and 11 on axes of azimuth angle, $\omega$, and the longitudinal distance from the airship nose, x. Fig. 10 is the pressure surface for a pitch angle of nine degrees and Fig. 11 is the pressure surface for a pitch angle of $20 \mathrm{deg}$. The magnitude of the maximum and minimum pressures for pitch angles nine and 20 degrees are shown within the plots. There is not a significant change in maximum pressure between these two pitch angles, however the minimum pressure is considerably lower (larger vacuum) for the larger pitch angle.

In this re-analysis, the dry air density was assumed to be $1.168 \mathrm{~kg} / \mathrm{m}^{3}$ for a temperature of $25 \mathrm{C}^{\circ}$ and barometric pressure of 100 $\mathrm{kPa}$, hence for the air speed of $100 \mathrm{mph}$ the free stream dynamic pressure is:

$$
\mathrm{q}_{0}=(1 / 2) \rho \mathrm{V}^{2}=(1 / 2) * 1.168 *(100 * 0.44704)^{2}=1167\left[\mathrm{~N} / \mathrm{m}^{2}\right]
$$

The maximum pressure for zero pitch angle is exactly equal to the dynamic pressure in equation (5) and for the other pitch angles it is close to that value. Table IV shows the maximum and minimum pressures for the eight different pitch angles tested. The longitudinal location and azimuth angle of the minimum and maximum pressures are included in Table IV; however, the pressure surface interpolation is not accurate up to three decimals as is shown for the maximum pressure location. Pressure contours give a better illustration of the pressure variation along and around the airship hull. Fig. 12(a) shows the pressure contours on axes of azimuth angle and the longitudinal distance from the airship nose for a pitch angle of 15 degrees.

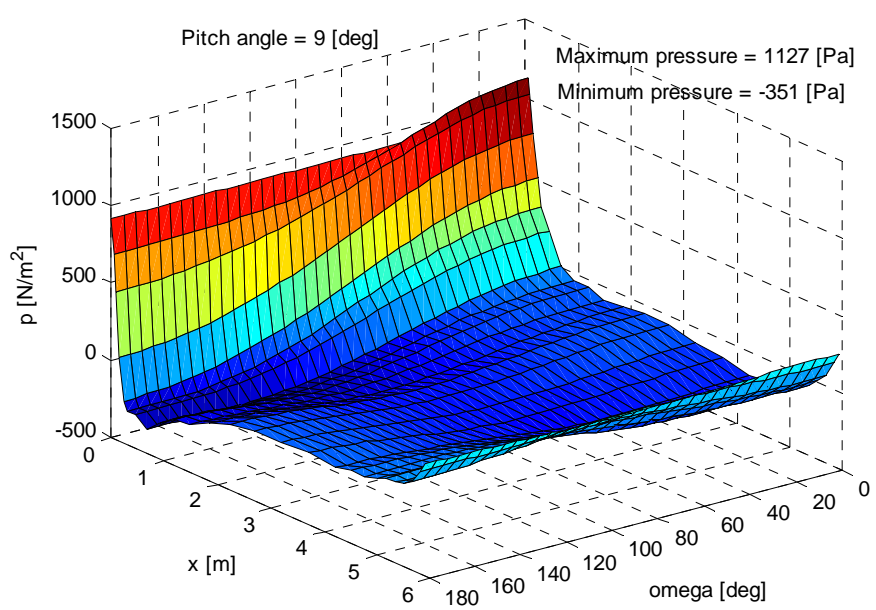

Fig. 10. Pressure distribution over the bare hull of the Akron airship for a pitch angle of $9 \mathrm{deg}$

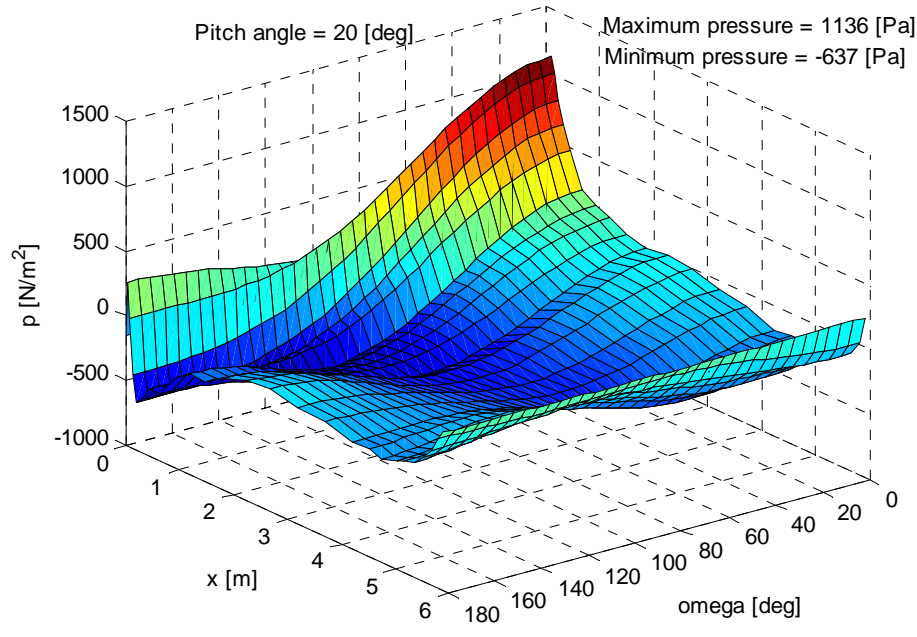

Fig. 11. Pressure distribution over the bare hull of the Akron airship for a pitch angle of $20 \mathrm{deg}$ 
TABLE IV.

Maximum and Minimum Pressures for Different Pitch Angles for the Akron Model at a Windspeed of $44.7 \mathrm{~m} / \mathrm{s}$

\begin{tabular}{|c|c|c|c|c|c|c|c|c|}
\hline Pitch angle $[\mathrm{deg}]$ & 0 & 3 & 6 & 9 & 12 & 15 & 18 & 20 \\
\hline Max pressure $\left[\mathrm{N} / \mathrm{m}^{2}\right]$ & 1167 & 1129 & 1109 & 1127 & 1132 & 1138 & 1132 & 1136 \\
\hline$\omega$ for max $[\mathrm{deg}]$ & - & 0 & 0 & 0 & 0 & 0 & 0 & 0 \\
\hline $\mathrm{x} / \mathrm{l}$ for $\max$ & 0 & 0.004 & 0.005 & 0.006 & 0.007 & 0.008 & 0.01 & 0.013 \\
\hline Min pressure $\left[\mathrm{N} / \mathrm{m}^{2}\right]$ & -187 & -247 & -291 & -351 & -387 & -451 & -559 & -637 \\
\hline$\omega$ for min $[\mathrm{deg}]$ & - & 170 & 160 & 150 & 140 & 130 & 120 & 115 \\
\hline $\mathrm{x} / \mathrm{l}$ for $\min$ & 0.12 & 0.12 & 0.12 & 0.11 & 0.11 & 0.11 & 0.1 & 0.1 \\
\hline
\end{tabular}

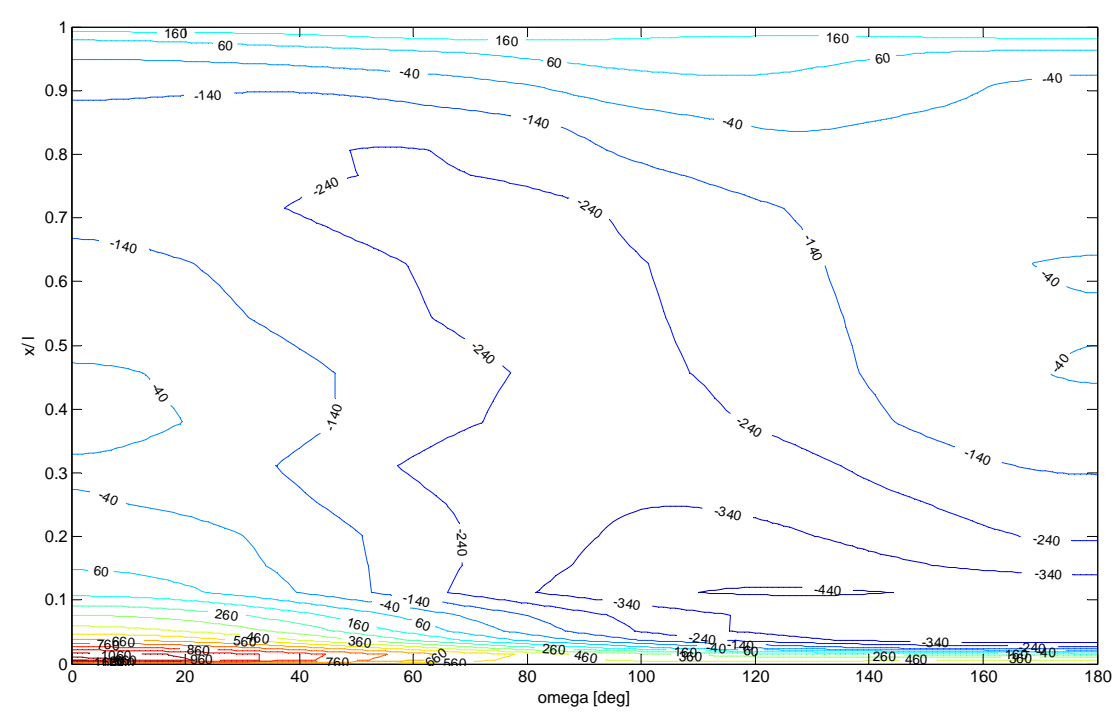

Fig. 12(a). Pressure contours over the bare hull of the Akron airship for a pitch angle of $15 \mathrm{deg}$

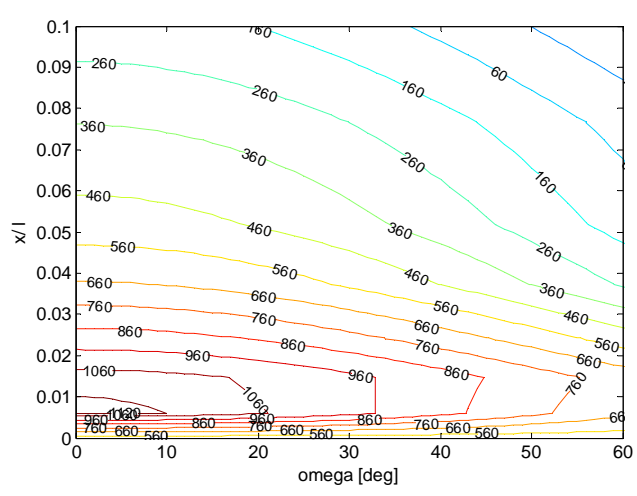

Fig. 12(b). Magnified region near the nose

In Fig. 12(a), the high-pressure zone at the airship nose is magnified and shown in Fig. 12(b). The highest-pressure contour, shown in the zoom-in, is $1120 \mathrm{~Pa}$, and the maximum pressure for the pitch angle of 15 degrees is 1138 according to Table IV.

The pressure distribution over the bare hull of an underwater vehicle should have the same pattern and same variation with pitch or yaw angle as for the airship for the same hull shape (if it is a body of revolution the effect of pitch and yaw attitude changes are the same). The pressures for an underwater vehicle that is towed at a speed of $3 \mathrm{~m} / \mathrm{s}$ in fresh water are scaled relative to the "Akron" airship surface pressures according to:

$$
\begin{gathered}
\text { (Underwater vehicle normal stresses/Airship normal stresses })=\left(\rho_{\text {water }} \mathrm{V}_{\text {towing }}{ }^{2}\right) /\left(\rho_{\text {air }} \mathrm{V}_{\text {air }}{ }^{2}\right) \\
=\left(1000 * 3^{2}\right) /\left(1.168 * 44.7^{2}\right)=3.86
\end{gathered}
$$

Therefore the maximum and minimum pressures occurring on the surface of the hull of an underwater vehicle (which has the same shape as the "Akron" airship) are roughly four times the values in Table IV.

\section{Pressure Integration OVer the 3D MEShed MODEL}

The fitted pressures were integrated over the meshed surface of the hull. For an arbitrary circumferential angle along the airship the differential normal force on each panel is:

$$
\Delta \mathrm{F}(\mathrm{x}, \omega)=\left(\mathrm{p} / \mathrm{q}_{0}\right) \cdot \Delta \mathrm{A}(\mathrm{x}) \cdot \mathrm{q}_{0}
$$

The first term in parentheses on the RHS of equation (7) is read from the polynomials of $9^{\text {th }}$ order. The elemental force resulting from equation (7) is perpendicular to the panel and should be projected in the directions parallel and perpendicular to the longitudinal axis of the hull. This is illustrated in Fig. 13(a), therefore the radial component of this force will be given by $\Delta \mathrm{F} \cdot \cos (\varphi)$ and the axial component by $\Delta \mathrm{F} \cdot \sin (\varphi)$, as follows:

$$
\begin{aligned}
& \Delta \mathrm{F}_{\mathrm{x}}=\Delta \mathrm{F} \cdot \sin (\varphi) \\
& \Delta \mathrm{F}_{\mathrm{r}}=\Delta \mathrm{F} \cdot \cos (\varphi)
\end{aligned}
$$

The component of force in the radial direction, $\Delta \mathrm{F}_{\mathrm{r}}$, should be projected into the lateral and vertical directions, as illustrated in Fig. 13(b). Hence, using equation (9) results in:

$$
\begin{aligned}
& \Delta \mathrm{F}_{\mathrm{y}}=\Delta \mathrm{F}_{\mathrm{r}} \cdot \sin (\omega)=\Delta \mathrm{F}(\mathrm{x}, \omega) \cdot \cos (\varphi) \cdot \sin (\omega) \\
& \Delta \mathrm{F}_{\mathrm{z}}=\Delta \mathrm{F}_{\mathrm{r}} \cdot \cos (\omega)=\Delta \mathrm{F}(\mathrm{x}, \omega) \cdot \cos (\varphi) \cdot \cos (\omega)
\end{aligned}
$$



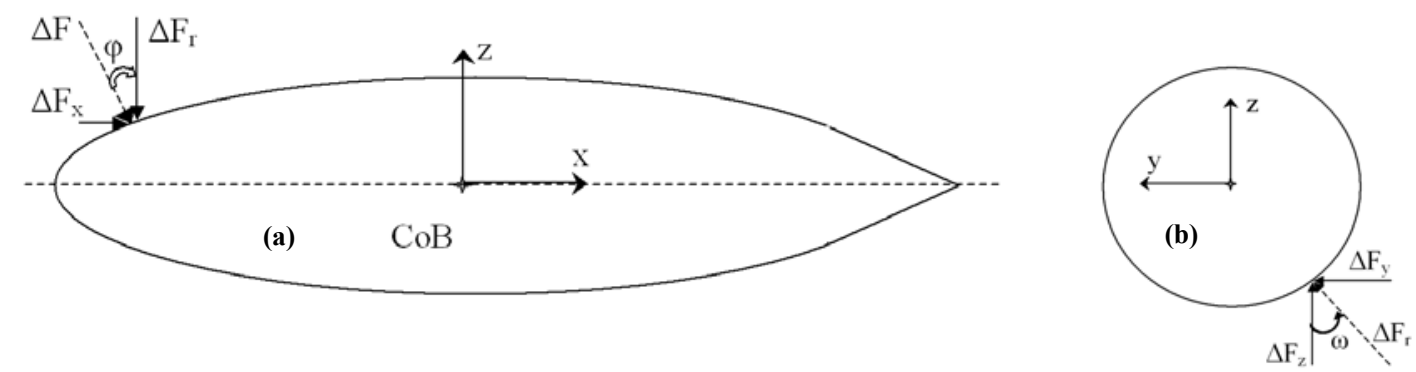

Fig. 13. Arbitrary elemental forces illustrated in: (a) side-view and (b) front view looking aftward (x-axis goes into the sheet)

Integration of the differential forces was performed along the hull for each increment $\omega$ of the circumferential angle; the sums are then accumulated around the hull for $0<\omega<180^{\circ}$ in order to obtain half of the total forces, and then multiplied by two since the flow is symmetric. Equation (8) gives the elemental axial force; the integration of $\Delta \mathrm{F}_{\mathrm{x}}(\mathrm{x}, \omega)$ over both $\Delta \mathrm{x}$ and $\Delta \omega$ will give the total axial force acting on the hull, which is expected to be zero for a pitch angle of zero. Equation (10) gives the elemental lateral force; the integration of $\Delta \mathrm{F}_{\mathrm{y}}(\mathrm{x}, \omega)$ over both $\Delta \mathrm{x}$ and $\Delta \omega$ will give the total lateral force acting on the hull, which is expected to be zero for any pitch angle as long as the yaw angle is zero, since the flow is assumed to be symmetric on the port and starboard sides. Equation (11) gives the elemental normal force; the integration of $\Delta \mathrm{F}_{\mathrm{z}}(\mathrm{x}, \omega)$ over both $\Delta \mathrm{x}$ and $\Delta \omega$ will give the total normal force acting on the hull, which is expected to be zero for a pitch angle of zero.

As illustrated in Fig. 14, relations between the axial and normal forces which give the drag and lift forces for a pitch angle of $\theta$ are:

$$
\begin{aligned}
& D=F_{x} \cdot \cos (\theta)+F_{z} \cdot \sin (\theta) \\
& L=F_{z} \cdot \cos (\theta)-F_{x} \cdot \sin (\theta)
\end{aligned}
$$

The pitching moment was calculated about the centre of buoyancy $(\mathrm{CoB})$. The differential force on each panel creates a moment; the axial component of the force has a moment arm equal to:

$$
\mathrm{d}_{\mathrm{x}}=\mathrm{r} \cdot \cos (\omega)
$$

and the vertical component of the force has a moment arm equal to:

$$
\mathrm{d}_{\mathrm{z}}=\mathrm{x}_{\mathrm{CoB}}-\mathrm{x}
$$

where the longitudinal location of the $\mathrm{CoB}$, according to [2] is: $\mathrm{x}_{\mathrm{CoB}}=0.464 \cdot 1=2.775 \mathrm{~m}$. The differential moment due to one panel is:

$$
\Delta \mathrm{M}_{\mathrm{y}}=-\Delta \mathrm{F}_{\mathrm{x}} \cdot \mathrm{d}_{\mathrm{x}}+\Delta \mathrm{F}_{\mathrm{z}} \cdot \mathrm{d}_{\mathrm{z}}
$$

Note that the directions of the positive axes are required to interpret the minus sign in (16). The circumferential angle, $\omega$, is zero at the keel and positive counterclockwise in a front view when looking aftward.

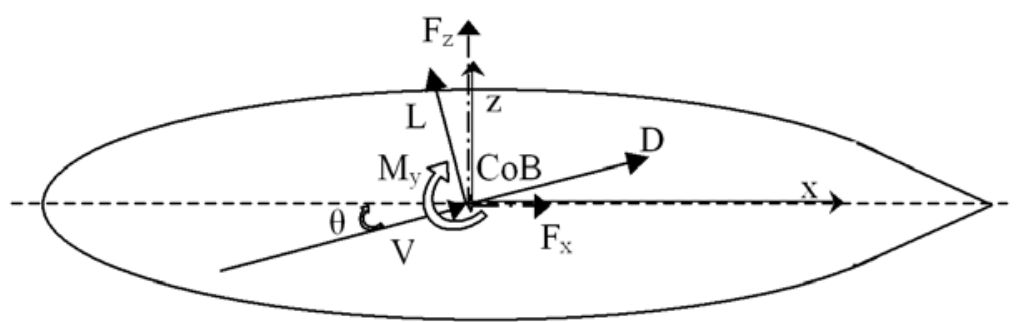

Fig. 14. Axial and normal forces and drag and lift forces illustrated

Figs. 15 to 19, respectively, show the axial force Fx (positive aftward), normal force (positive away from the keel), drag force (positive downwind), lift force (positive upward), and pitching moment (positive nose upward). Each figure has been plotted for several mesh-sizes with the smallest and largest increments for $\Delta \mathrm{x}$ and $\Delta \omega$ of respectively: 0.01 and $0.2 \mathrm{~m}$, and 1 and 30 degrees. The mesh-size $[\Delta \mathrm{x}, \Delta \omega]$ of $[0.01 \mathrm{~m}, 1 \mathrm{deg}]$ is an extremely fine mesh for a hull which is almost $6 \mathrm{~m}$ long. For the axial force, normal force and pitching moment the reported results from [2] are also shown with square markers. For the axial force, $\mathrm{F}_{\mathrm{x}}$, the NACA reported result found from a 2D integration has large errors compared to the 3D panel method used here. In the NACA report, no values were reported for pitch angles of 18 and 20 degrees; interpolated results are now available for these two pitch angles. The integrated values for the axial force with fine mesh sizes for a zero pitch angle converge to a value of 6.5 [N]. This axial force is the pressure-drag as can be observed in Fig. 17 for pitch angle of zero. Up to a pitch angle of 15 deg the axial force is about the same value, however decreases from there to negative values for the larger pitch angles. For the pitch angle of 20 degrees the integrated axial force is about $-16.5[\mathrm{~N}]$. 


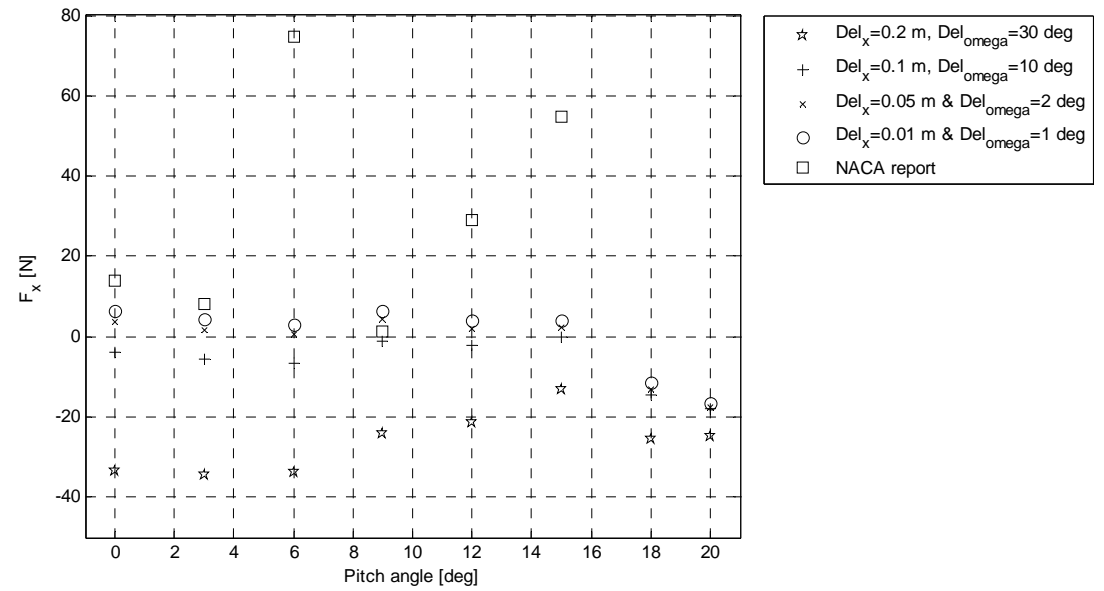

Fig. 15. Axial force vs. pitch angle for various mesh sizes compared to NACA report

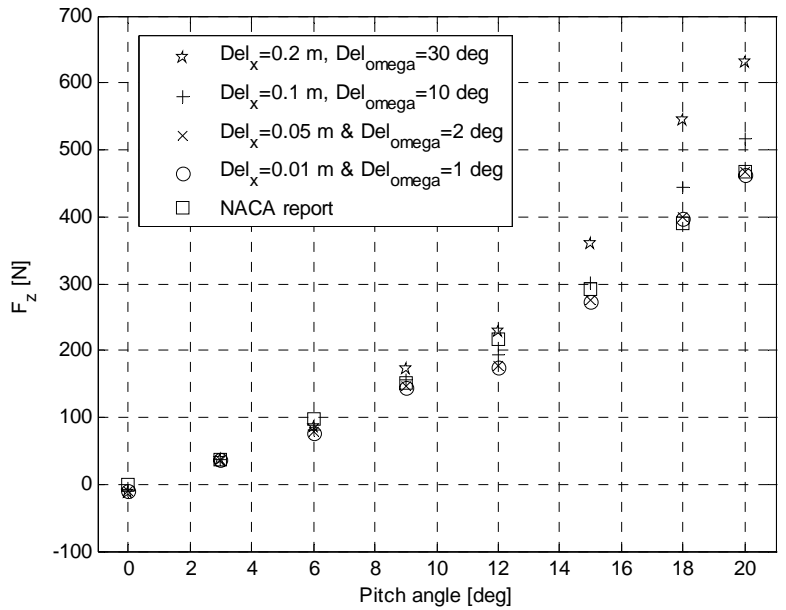

Fig. 16. Normal force vs. pitch angle for various mesh sizes compared to NACA report

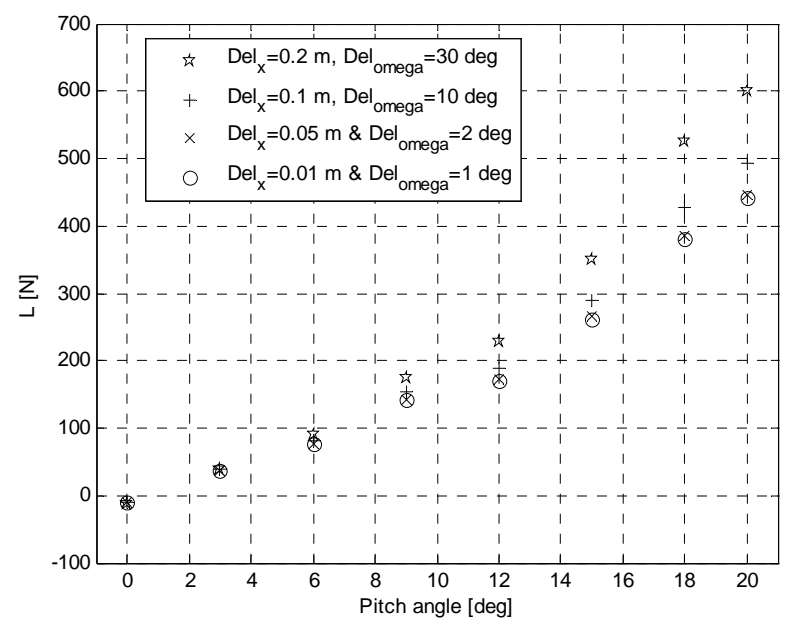

Fig. 18. Lift force vs. pitch angle for various mesh sizes

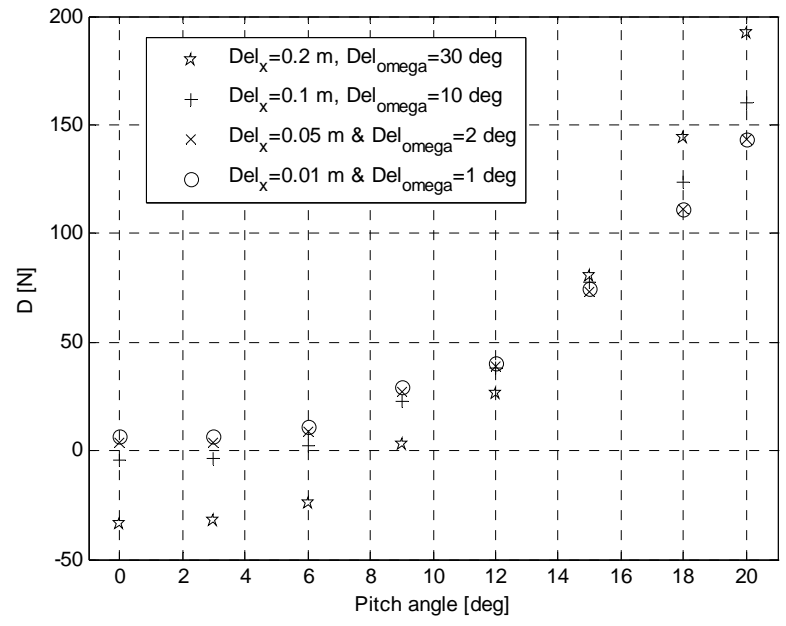

Fig. 17. Drag force vs. pitch angle for various mesh sizes

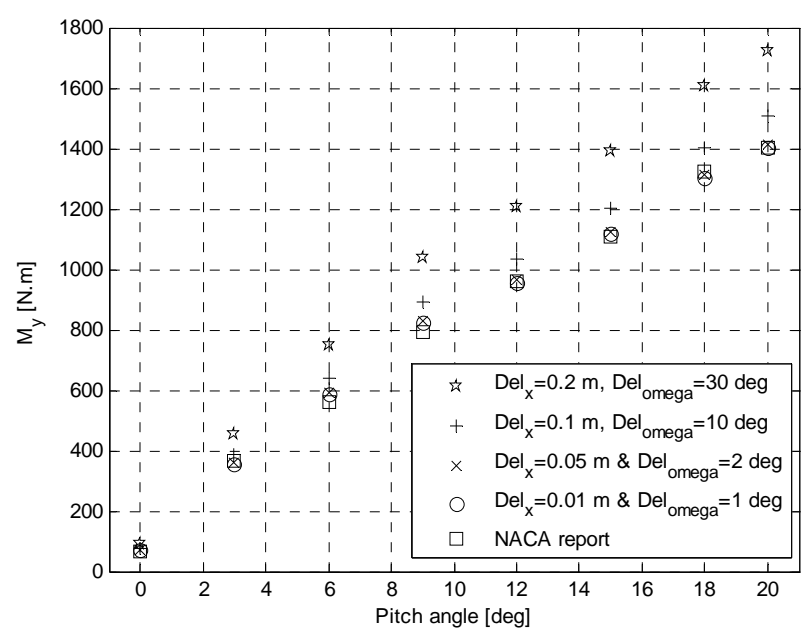

Fig. 19. Pitching moment vs. pitch angle for various mesh sizes

Except for the axial force results, the other forces resulting from the 3D fine mesh size integration approach the reported NACA results, even though the latter used the relatively simple 2D integration methods. As can be observed, there are large differences between the computed forces and moments for the fine mesh size with $[\Delta \mathrm{x}, \Delta \omega]$ of $[0.01 \mathrm{~m}, 1 \mathrm{deg}]$, and for the coarse mesh size with $[\Delta \mathrm{x}, \Delta \omega]$ of $[0.2 \mathrm{~m}, 30 \mathrm{deg}]$. 


\section{Pressure MeAsurements on a MANOEUVRING UnderWATER VehiCLE}

In our present study of the hydrodynamics of Autonomous Underwater Vehicles (AUVs), employing mostly experimental methods, a method to extract the dependence of the hydrodynamic loads on the vehicle characteristics and the manoeuvring parameters is desired. In addition to the fixed-attitude manoeuvres as in the "Akron" experiments, variable-attitude manoeuvres with underwater vehicles including high-amplitude, high-rate manoeuvres, such as those which occur during obstacle avoidance, have to be performed. Measurements of the overall hydrodynamic loads with an internal balance have already been performed and some results have been presented in [5] to [8]. The main motivations for pressure measurements are:

1) To know the pressure distribution over the underwater vehicle. Pressure distribution information will result in knowledge of the locations of the maximum and minimum pressures, the pressure gradients, and locations of flow separation.

2) To evaluate the hydrodynamic loads by integrating the pressures. Pressure transducers only measure the normal pressure; therefore, the viscous effect that results from the shearing stresses is not taken into account in the integration. The differences between the hydrodynamic loads resulting from direct load measurement and from pressure tests will clarify the contribution of viscous shearing effects. Note that there is a viscouse pressure axial force as was shown in Fig. 15.

The first stages in these measurements are the straight-line towing and static yaw tests, which are very similar to the "Akron" tests. One major difference is that the airship was tested in a wind tunnel with the fluid passing over it, however in these tests it will be necessary to tow the vehicle through stationary fluid.

\section{CONCLUSIONS}

For the study of AUVs (Autonomous Underwater Vehicles) at the NRC-IOT (National Research Council - Institute for Ocean Technology) pressure measurements over the bare hull of an AUV model towed with a variable attitude apparatus (Planar Motion Mechanism) in the calm towing tank water will be performed. To approximate the distribution and magnitude of pressures over the bare hull of an AUV and the resulting forces and moment, the best available resource is the pressure data from the US airship "Akron" tested by the NACA in 1932.

A re-analysis of the Akron pressure data utilizing modern numerical tools resulted in:

a- Plots of pressure distribution versus the azimuth angle and the longitudinal distance from the airship nose. Hence, one can know where the maximum and minimum pressures occur for each pitch angle. Also these data will be useful for those people who wish to validate their CFD predictions using experimental results.

b- Drag and lift forces and pitching moment show nonlinear variations versus pitch angle resulting from the measured normal stresses. This can be compared to the total forces and moment including shear stresses.

c- An error estimate for the panel method due to the errors in curve fitting, errors in data interpolation and errors in integration (not presented in this paper).

With this basic knowledge the design of the pressure-measurement experiments for an AUV will be done.

\section{ACKNOWLEDGMENT}

The authors would like to thank the staff of Memorial University and NRC-IOT for their technical assistance.

\section{REFERENCES}

[1] Hugh B. Freeman, Force measurements on a 1/40-scale model of the U.S. Airship "Akron”, Report No. 432, N.A.C.A, 1932

[2] Hugh B. Freeman, Pressure-distribution measurements on the hull and fins of a 1/40-scale model of the U.S. Airship "Akron", Report No. 443, N.A.C.A, 1932

[3] Hugh B. Freeman, Measurement of flow in the boundary layer of a 1/40-scale model of the U.S. Airship “Akron”, Report No. 430 , N.A.C.A, 1932

[4] SNAME 1950, The society of naval architects and marine engineers. Nomenclature for Treating the Motion of a Submerged Body Through a Fluid, Technical and Research Bulletin, No. 1-5.

[5] Williams, C.D., Curtis, T.L., Doucet, J.M., Issac, M.T., Azarsina, F., "Effects of Hull Length on the Manoeuvring Characteristics of a Slender Underwater Vehicle", OCEANS'06 MTS/IEEE-Boston Conference, September 18 to 21, 2006

[6] Azarsina, F., Williams, C.D., Lye, L.M., "Resistance and Static Yaw Experiments on the Underwater Vehicle "Phoenix"; Modeling and Analysis, Utilizing Statistical Design of Experiments Methodology", OCEANS'06 MTS/IEEE-Boston Conference, September 18 to 21, 2006

[7] Azarsina, F., Williams, C.D., Issac, M.T., "Pure Yaw Experiments on a Series of Hull Forms for an Underwater Vehicle: Hydrodynamic Observations and Analysis", International Symposium on Underwater Technology, Tokyo, Japan, April 17 to 20, 2007.

[8] Azarsina, F., Williams, C.D., Bachmayer, R., "Response Surface Models for the Hydrodynamic Loads Measured on Slender Underwater Vehicles During Pure Yaw Manoeuvres", $15^{\text {th }}$ Symposium UUST, Durham, New Hampshire, August $19^{\text {th }}-22^{\text {nd }}, 2007$ 